\title{
Rehabilitating Prisoners: The Place of Basic Life Skills programmes
}

\begin{abstract}
Purpose - Tackling high reoffending rates in England and Wales is of significant political interest, with education and training being viewed as an important mechanism to achieve change. This paper presents the findings of a small empirical study examining a life skills programme delivered in a Category C prison in the West Midlands.

Design/methodology/approach - The study used a multi-method approach incorporating observations of two modules, four focus groups with prisoners enrolled on the programme, questionnaires with programme completers, and semi-structured interviews with staff.

Findings - The findings indicate that life skills are an important component in rehabilitation. More specifically, developing the necessary tools to assist prisoners in everyday life, such as recognition, interpretation, reflection, response, and planning is fundamental to rehabilitation.

Research Limitation s/Implications-A limitation of this study was that only prisoners currently at this Category $C$ prison were included. This could be complemented by the inclusion of more participants who had completed the programme, however access and data protection considerations limited the study to one location.

Practice Implications - The key message of this study is that without addressing basic life skills, education and vocational rehabilitation is severely limited.

Social Implications - To reduce reoffending rates it is important to conceive rehabilitation in broader terms, not simply in relation to education and vocational training.
\end{abstract}

Originality/Value - This paper offers insight into an unreported area of good practice in prison rehabilitation provision.

Keywords - Life Skills, Rehabilitation, Education, Thinking Skills, Prison, Prisoner, Reoffending.

Paper type Research paper

\section{Introduction}

The high rate of imprisonment in England and Wales has culminated in a prison population of 86,720 (Ministry of Justice, 2017). Of equal concern is the rate of reoffending reported by the Ministry of Justice (2015b) of around 45 percent within 12 months of release for longer term prisoners and considerably higher for those receiving 12 months or less. Such reoffending rates raise doubt about the sustainability of prison as an environment for change. especially at a time when cost reduction and value for money are key political priorities. For example, desistance from crime is not solely down to an issue of individual desire or motivation but is interlinked with wider social and economic conditions, including unemployment, poverty and social exclusion. As noted by Behan (Behan, 2014:28) 'change does not occur in a vacuum', therefore to reduce reoffending an individual's social and human capital must also be developed to reinforce desistance efforts upon release (c.f. Wolfgang et al. 1987; Laub and Sampson, 2001; Benson, 2013). However, in responding to these doubts the central approach has been to scrutinise education and training provisions within prison (Coates, 2016). These provisions have undergone considerable change, shifting from delivery through local education 
authorities to contracting out provisions to external providers and private companies. Delivery of prison education has been the responsibility of the Offenders' Learning and Skills Unit (OLSU) since May 2003, at the heart of which is a recognition that prisoner education should be flexible and learner centred (Braggins and Talbot, 2003). However, a review by Braggins and Talbot (2003) argues that education and training options are highly restricted and taken out of the hands of the prisoner, thus reducing their level of ownership in rehabilitation and progression. This is further constrained by the refocusing of resources away from accredited General Offender programmes toward more specialist Domestic Violence and Violence programmes since 2009/10, together with a general downward trend in both retention and completion of General Offender programmes, leaving a distinct gap in provision (MoJ, 2015a). In addition, Hurry et al (2012) consider prison education provisions to be too narrow, focusing predominantly on employment-orientated skills and statutory education, which minimises prisoner opportunity. Unquestionably, education and vocational training are fundamental components of rehabilitation, necessary for maximising chances in the increasingly competitive employment market post-release (Keena and Simmons, 2015). Conversely, focusing too heavily on such programmes may come at the expense of other equally important skills, such as life skills.

The term 'life skills' is open to wide interpretation and thus, difficult to define. However, the World Health Organisation (WHO,1999:3) identified four basic life skills as '...self-awareness, problemsolving, criticalthinking, and interpersonal skills'. These have been derived from an understanding of life skills as abilities that if learnt and practised, can facilitate wider pro-social skills such as empathy and self-esteem. The WHO (1999) contend that, by teaching life skills, basic education, citizenship, quality of life, lifelong learning and equality can be enhanced. Such skills extend beyond the scope of Thinking Skills Programmes, formal education, and/or vocational training; thereby raising the question of whether rehabilitation can be wholly successful without first addressing the absence of life skills. Whilst it must be acknowledged that such skills are founded upon life experience and consequently, may be difficult to teach in a traditional sense, where such opportunities are absent or inadequate, attempts to bridge this gap are necessary. Recognition of this need is starting to emerge in the United Kingdom (UK) with writers such as Behan (2014) and Warr (2016) arguing that effective prison education needs to move beyond the current focus on numeracy and literacy provisions, and cognitive behaviour interventions, and acknowledge the place of fundamental life skills in the rehabilitation process. These arguments are particularly salient considering that life skills teaching may assist with the reduction of violence, substance misuse, suicide, and conflict (WHO, 1999); all of which pose considerable challenges to the prison system. 
It could therefore be argued that where life skills are not sufficiently developed a prisoner's ability to successfully engage in education or vocational programmes may be hindered, thus impacting their future capability to reform. It must also be recognised that the importance of life skills stretch beyond the current focus on education and vocational training to wider issues of housing, financial support, and mending or building relationships, all of which are fundamental elements of rehabilitation. To some extent this criticism has been acknowledged in the Transforming Rehabilitation: A Strategy for Reform paper (MoJ, 2013), which notes the importance of securing wider provisions by harnessing the work being done outside the traditional criminal justice system. In principle, at least, the paper suggests a need for flexible and innovative provisions if prisoner reform is to be successful. However, in the face of austerity measures the provision of alternative flexible and innovative programmes, such as life skills programmes is limited. Due to this, empirical research in this area is necessary, yet the extent and nature of alternative programmes remain vague. This is not to say that life skills work is not being done in prisons, just that the current prison curriculum focuses on the 'what works' agenda (Cullen, 2013). This results in a heavy emphasis on psycho-educational or psycho-social programmes such as cognitive behavioural approaches which, according to Behan (2014:27; emphasis in original) reframes 'education as treatment [reducing] the individual to a patient, a subject, somebody that something is done to, rather than with'.

One of the most widely used cognitive behavioural programmes is the Thinking Skills Programme (TSP), developed from the Enhanced Thinking Skills (ETS) programme to accommodate new developments in theory, research and practice (Harris and Riddy, 2008). Studies exploring the earlier ETS programme yielded mixed results with some studies suggesting the reduction in reconviction rates after one to two years (Friendship et al, 2002), while others found no significant impact (Falshaw et al, 2003; Cann et al, 2003), or impact only associated with certain offences (Travers, Mann and Hollins, 2014). The Joint Prison and Probation Review in 2005 recognised this inconsistency in reconviction rates and replaced ETS with TSP in 2009. TSP maintains the cognitive behaviour approach but incorporates new treatment targets (Gobbett and Sellen, 2013; Riddy, 2010). While there is a growing body of literature documenting the programme's success with specific skills or changes in thinking (Blud and Travers, 2001; MacKenzie, Bierie and Mitchell, 2007; Barrett, 2008; ), Gobbett and Sellen (2013) argue that measuring change in thinking is not necessarily synonymous with changes in behaviour. They caution that prisoners may use such programmes to control their progression or pending release rather than internalising their learning and truly changing their behaviour. In effect '...repeating... what they have been taught to say on a programme' (Gobbett and Sellen, 2013:457) or 
as Behan (2014:27) posits 'give[s] the appearance of change through conformity, rather than an authentic personal transformation'.

A further problem identified with this rehabilitative approach is the use of entry requirement, usually based on risk and need assessments, making the uptake of such programmes conditional and exclusionary. For example, a reasonable level of numeracy, literacy and IQ levels are necessary prerequisites of TSP, however a large proportion of prisoners enter prison with a knowledge of Maths or English equivalent to primary school level (Coates, 2016), thus excluding TSP as an option. This suggests that readdressing educational attainment rather than thinking skills is of greater importance yet even where such provisions are available, Coates (2016:iii) reports that 'three fifths of prisoners leave prison without an identified employment or education or training outcome', highlighting a worrying gap in provision. While the Coates Report (2016) emphasises the importance of education, training, and personal and social development, in practice the latter is rhetoric overshadowed by a focus on the first two which subsequently underplays the necessity for basic life skills development as a means of improving access and attainment in other areas. Considering that basic life skills are developed through interactions within school, home and social environments and bearing in mind that 42 percent of prisoners' report having been excluded from school and/or growing up in care (Williams, Papadopoulou and Booth, 2012), it seems plausible to suggest that such circumstances constrain the development of basic life skills.

Unfortunately, programmes orientated around basic life skills within prison appear to be a neglected area in the UK or at least one that is underreported. However, examining literature from outside the UK suggests that attempts to bridge this gap are gaining momentum. Programmes such as Power of People (POP) (Clark and Duwe, 2015) offer a broader, more inclusionary approach to rehabilitation rather than measurable literacy, numeracy and IQ levels. For example, entrance to such programmes is conditional on basic requirements such as the ability to attend weekly, sufficient time left on the prisoner's sentence to complete the programme, and being at a facility running the programme. Furthermore, Clark and Duwe (2015) reported good rates of retention and completion (73\%), in comparison to programmes across England and Wales (MoJ, 2015a), and a lower rate of recidivism in terms of re-arrest, for those completing the programme. Likewise, Keena and Simmon's (2015) evaluation of an entrepreneurial programme for maximum-security prisoners found that orientating the programme around key life lessons, better prepared prisoners for the challenging employment market post-release. This orientation included taking responsibility for their actions, recognising opportunities, problem solving, moving from a fixed to a growth mindset, and helping others. Similar 
developments can also be seen in the work of McNeil (2006), and Weaver (2015) amongst others. Building on this body of work, the Chrysalis programme being examined in this paper supports the argument that more flexible provisions are needed that focus on, or develop life skills as part of rehabilitation. In short, not everyone gains the essential life skills necessary to negotiate society and while this issue is not unique to prisoners, their upbringing, lifestyle, and the revolving door scenario they often find themselves in, actsas a further barrier to obtaining them.

The Chrysalis programme has been running in varying forms and at several prisons across England since September 2009. The programme's rationale is that offending behaviour is influenced by a lack of essential life skills, especially among prolific offenders. As such, Collinwood's (2010) The 7 Habits on the Inside: Reducing Recidivism through Behaviour Change provides the organisational rationale for the programme. This approach views prisoners as leaders of their own lives and families, therefore it emphasises behaviour change in the form of proactivity, goal directedness, prioritization, win-win thinking, empathic listening, the value of cooperation, and vigilant self-renewal (Collinwood, 2010). Based on an adaptation of these ideas, the Chrysalis Lite version being examined here, operates on a modular basis with a workbook attached to each interactive session. It incorporates six of twelve modules which translates to eight days of interaction and learning over six weeks. The structure is unique in the sense that it is tailored to the needs of each cohort, for instances those nearing release may take modules with a heavy employment or reintegration skills focus, while those earlier in their sentence might focus more on attitude, health and life planning skills. Whatever scenario, general topics covered include health, thinking skills, legal issues, life planning, housing, education, employment, interpersonal and social skill development. What makes Chrysalis Lite stand out from other rehabilitation programmes is the emphasis on 'essential life skills' alongside education and training. In terms of output, programme data suggests a high level of uptake with 94 percent of places offered between September 2009 and May 2015 being filled, alongside an 86 percent retention rate and 90 percent completion rate (Apparicio, 2015). Furthermore, although Chrysalis Lite is not accredited by the National Offender Management Service (NOMS), a level 2 City and Guilds qualification is available and of the 75 percent of participants who have taken the test, 90 percent were successful.

Various explanations for this apparent success have been offered, first Chrysalis Lite is not accredited by NOMS and thus allows for greater flexibility in terms of content, delivery, and enrolment. Enrolment is based on the prisoner's ability to attend and complete the programme, alongside a willingness to engage, rather than standard prerequisites based on risk, need, or minimum 
educational attainment. In addition, because the programme runs over six weeks it accommodates prisoners on shorter sentences (less than 12 months), thus targeting a recognised problematic group in terms of reoffending (59.3 percent) (MoJ, 2015b). Second, enrolment and engagement with Chrysalis Lite was reported by prisoners' to be self-driven (voluntary) rather than directed by their Offender Manager or sentencing plan. This motivation was linked to recommendation from other prisoners and prison staff, with participants emphasising that positive feedback on programmes was unusual thus "word of mouth holds real status" (Jacob). Third, 'mandatory' programmes were often seen by prisoners as a tick box exercise where they learnt what they needed to say to pass the programme, whereas Chrysalis Lite "is open enough to allow you to think for yourself and say what you think" (Brian). This may link to an issue of accreditation and the fact that the programme's not accredited by NOMS, resulting in greater flexibility and thus a less scripted approach to content development and delivery. This, in turn, may also explain the development of various basic life skills found by this study.

\section{Method}

This evaluation was commissioned by the Chrysalis foundation and supported by the Category C adult male prison hosting the programme at the time of the study. The evaluation was concerned with mapping out the potential success of various elements of delivery against the programmes main aims and objectives, albeit only a small element of that evaluation is being focused on here. The aims of Chrysalis are to 1) reduce re-offending rates or the escalation of offending severity; 2) engage and inspire sustainable change in individuals; 3 ) create a paradigm shift in the approach to offender development and re-integration through thinking, attitude, learning, and behaviour development; 4) engage individuals to make behavioural changes that they want to achieve; and 5) to create switchedon, motivated, re-engaged and re-integrated individuals who are driven to contribute to their local communities and society (Apparicio, 2015). The evaluation strategy included a flexible examination of process, expectation, and context (Semmens, 2011). Following this inductive approach qualitative data was gathered using a multi-method approach incorporating observations, focus groups, questionnaires, and semi-structured interviews. Conducting research in a prison environment comes with a host of constraints and to this end the sampling approach taken was one of opportunity sampling (Bryman, 2008), while data collection was confined to extensive note-taking because of restrictions on electronic devices in prison. A transcript was compiled from the notes and analysed using thematic analysis (Boyatzis, 1998; Bryman, 2008) with all participant names replaced with pseudonyms and identifiable institutional details removed. 
Observations of three of the six available modules were undertaken over two full days. The research also involved participation in a module in the same manner as other participants in the hope of dispelling the perception that the prisoners rather than the programme were being observed. This also added a 'realistic' dimension to the findings with extensive, reflective notes taken during and after participation that were analysed in conjunction with the main observational data. While consideration was given to the potential bias this might have on the data, the potential benefits in terms of improved rapport and greater insight were deemed to outweigh the potential harm.

Four focus groups were conducted with 24 of the 30 enrolled on the programme. Each focus group lasted for 10 to 15 minutes and was conducted in the teaching space during structured breaks in the programme. To minimise outside influence, the programme facilitator and mentors were asked to leave during the focus groups. Each focus group focused on key themes including prisoner experience, attitude changes, and impact on behaviour. For the reasons outlined above, the data was gathered manually and notes were typed up at the earliest opportunity.

In addition, open ended, qualitative questionnaires were distributed to 50 Chrysalis completers still residing at the host prison, 11 of which were returned (22\%). The questions explored motivation to do the course, specific learning, examples of the application of this learning in day-to-day lives, and how their experience of Chrysalis Lite compared to other education programmes. Due to potential literacy difficulties, mentors (prisoners with mentor training and privileges) were on hand to assist anyone needing help to complete the questionnaire. It is acknowledged that this approach may lead to some bias in the data and encountered similar issues to postal questionnaires in terms of low response rates (Bryman, 2008), however this was the most feasible method for this target population and institution.

Finally, five semi-structured interviews were conducted, one with the Chrysalis Lite facilitator and four with prison operational staff. The interviews sought to gather data pertaining to the attitudes, opinions and experiences of those directly and indirectly involved with the programme and its participants. Once again manual notes were taken at the time of interview and written up at the end of the day.

\section{Findings}

Analysis of the data identified that through the programme prisoner's reported having developed greater self-awareness, problem-solving, critical thinking and interpersonal skills all of which have 
been categorised as life skills (WHO, 1999). The development of these skills came from a variety of tasks on the programme and have been organised here into three areas. The first of these related to time management, self-management, and organisations skills, reflecting the basic life skills of selfawareness, interpersonal skills, and autonomy. The second involved leadership and presentation skills, which developed the above skills further by incorporating problem-solving and critical thinking skills. The third related to what the participant referred to as 'living in the gap' which incorporated a range of interpersonal, problem-solving, and critical thinking skills. The development of the skills interlink with the basic behavioural changes outlined above, which Collinwood (2010) considers necessary for changing a prisoners' worldview and thus reducing the risk of reoffending.

\section{Basic Life Skills: Time Management, Self-management and OrganisationalSkills}

Participants in this study identified that Chrysalis Lite had helped them to develop basic life skills in relation to time management, self-management, and organisation, which they also considered important for rehabilitation. It was noted that as prison schedules are highly structured impacting prisoner autonomy, the ability to manage and balance time once released is an essential skill. Examples of this included moving from closed to open prison conditions as noted by Adam, “...looking longer term so I have more time because I know what I have time to do" (current cohort). Likewise, James indicated, "I'm already planning what I'm gonna do when I get out of prison, business wise" (current cohort), similarly Mark said "planning for the future was a skill I took from the course and I am currently working towards my 2-year life plan that I drew up on the course" (completer). One of the reasons this was considered an essential life skill was because many of the participants' felt that planning for the future was new to them, traditionally they "...never planned for 10 to 20 years before, only one day at a time" (Adam). However, it was also recognised by all participants that planning alone would not necessarily counteract the challenges they would face upon leaving prison, but they felt that the level of focus and drive they had gained from the task would at least help them to face these challenges head on. Matt, for instance acknowledged that achieving his goals may not be straight forward but noted that he had "a weekly/monthly/yearly planner, sometime I can deviate off the path but with the planner I can soon get back on it" (completer). This task also appeared to encourage some of the participants to engage with education, with one participant having enrolled on a degree programme with the Open University, another went onto complete a mentoring programme so they could come back to Chrysalis as a specialist mentor, and a further two felt that Chrysalis had enabled them to reflected on the benefit of other programmes they had already taken. Steve discussed education in terms of learning, noting that he had opted to do Chrysalis multiple times because "[it] can be hard to take it all in so each time I'm learning new things...that reinforced my expectations and 
what I learnt the first time" (completer). Likewise Chris suggested that Chrysalis was "actually teaching us something, something we can use" (completer). Finally, others utilised these skills to plan or engage with employment, either in prison (i.e. mentoring/catering) or once released (i.e. self-employment, office work).

\section{Basic Life Skills: Leadership and Presentation Skills}

A further life skill participants took from the programme involved them understanding themselves better to achieve sustainable change. It was clear that achieving sustainable change involved several stages, the first being self-reflection. One task showed that many of those taking part in the Chrysalis Lite programme had very low self-esteem, favouring negative descriptors to describe themselves. These descriptors included 'secretive, closed, and unattractive' which, interlinked with poor decisionmaking and self-presentation. Thus, the programme focuses initially on raising self-esteem and selfperception, enabling participants to improve positivity and reflect this in their presentation to others. For example, Ryan reported that "[Chrysalis] gave me a better insight into how I can be seen by others and not how I think I am!! And this can make a huge impact on making my personal brand better" (completer). He elaborated further on his personal brand saying, "I try to be the best I can be at all times as if I am constantly having an interview". This notion of personal brand or self-presentation was raised by most participants as an essential life skill because it helped them to remodel and present themselves more positively. This was illustrated in Rob's comment, "I think a lot more about how I come across to both staff and prisoners as I am aware that my actions have a knock-on effect in all my relationships" (completer), and Richard's suggestion that Chrysalis helped him “...learn how to run my own business and how to present yourself effectively, communication skills, team building" (completer).

Further examples of leadership and presentation can be seen in Steve's reflection that after completing the programme he went on to train as a prison mentor, noting "I wouldn't have stood in front of a class before, [it] points you in [the] right direction [making you aware of your] strengths and weaknesses". Similarly, other participants indicated that their communication skills and working with others had improved because of the life skills they had been learning. The most resounding example, which they perceived to be impacting their day-to-day lives, was 'living in the gap'.

\section{Basic Life Skills: Living in the Gap}

Living in the gap appeared to involve a combination of thinking, listening, interpretation, reflection, response, and presentation skills all of which are life skills necessary for conflict resolution, team work, 
stress management and problem solving. Broadly speaking, participants described living in the gap as the space between an action and a response, whereby the action is interpreted and a suitable response is devised. Nearly all of the participants felt that they did not have this skill before taking the programme which meant that instead of thinking about their response they would simply react. Through the module entitled ' 7 habits' the participants noted that they developed better listening skills which enables them to pause and consider the various meanings of an action before deciding on what their response would be and how to communicate that effectively. When asked about this Andrew responded:

I learnt to live in the gap. In other words. When things happen to me in life, I take a moment to evaluate what (and why) [it] has happened so that I can have a balanced and positive response to what has happened. Things are not always what they seem and so I now try to look at things from all different angles (completer).

He further explained that,

When someone is short...impatient with me I try to understand things from their point of view. Maybe they are having a bad day, or they've had some bad news for example. In evaluating this I see things differently than before and look to mediate or move on rather than react.

Most notably, these changes appeared to be related to interactions with staff whereby participants felt that their attitude towards prison staff had improved, resulting in easier, more relaxed interaction with officers. Reflecting on this Barry suggested that "...staff can be funny with us sometimes so we react accordingly, learning how to control yourself is important" (current cohort), similarly Ryan said that "...if a situation arises and I think of acting I try to take a break/step back and be in the gap between thinking and doing" (completer). In short, living in the gap appears to develop understanding skills, belief that they can influence an outcome, communication skills, team work and co-operation, and listening skills. By taking a moment to think rather than immediately reacting, these life skills influence prisoners to adopt a do-think rather than a think-do approach to life events and thus better prepare them for life outside.

Changes in participants' behaviour was also reported by prison staff, one of whom noted "...a visible change in behaviour between weeks one and three. Often the types of conversations they are having have changed..." and that the programme enabled individuals to learn how to ask things in a more appropriate way, having a positive impact on prisoner-staff relations. Alongside prisoner-staff relations, prisoner-prisoner relations also appeared to be improved by this notion of the 'living in the gap', most notably in relation to violent outbreaks. Some prisoners and staff felt that Chrysalis Lite was helping to reduce levels of violence often associated with feelings of frustration and anger. This 
can be seen in Steve's reflection that "...I was angry when I came to the prison but the course helped me to realise that I needed to move on" (completer). Others reflected that learning to live in the gap helped them control their temper which was also visible to staff, one of whom suggested "...[the] Chrysalis programme [helps to] resolve violence or reduces it and encourages thinking".

\section{Discussion}

The purpose of this paper was to present some of the findings from a small scale empirical study examining a life skills programme being offered to prisoners in a Category $\mathrm{C}$ adult male prison in England. While the study itself focused on evaluating the extent to which Chrysalis Lite met its own objectives, the intention here was to explore the place of basic life skills development in rehabilitation, arguing that the absence of such skills make engagement with traditional educational and vocational programmes challenging. The first point to draw from the findings relates to levels of engagement with rehabilitative programmes more widely. In contrast to the declining trend in retention and completion rates on General Offender programmes reported by the Ministry of Justice (2015a), the Chrysalis Lite programme, like the POP programme (Clark and Duwe, 2015), demonstrated good rates of enrolment, retention and completion, therefore it may be possible to draw some insight into more effective ways of engaging the target population elsewhere. For example, in terms of research and practice implications, the findings of this study suggestion that programmes need a more innovative and less restrictive approach to prisoner rehabilitation. One area in which this might be possible is programme choice. If prisoners are recognised as autonomous individuals who are 'agents in the process of change' (Behan, 2014:21) then a degree of ownership over the programmes they do is necessary. The ability to voluntarily take a programme rather than being instructed to was certainly deemed important by the participants in this study. Furthermore, since prisoner's needs are often managed for them rather than by them, linking to Behan's (2014:27) argument that education has been reframed as treatment where 'something is done to, rather than with' prisoners, the voluntary nature of Chrysalis Lite recognises the need for prisoner ownership in rehabilitation and progression highlighted elsewhere (Braggins and Talbot, 2003; Coates, 2016).

Adopting such an approach presents several challenges that may be difficult to overcome. The first relates to the use of sentencing plans which some participants felt were used against them '... as a form of entrapment...a tool to hold you back from DCAT" (William: current cohort). Although this claim was not verified, similar concerns have been raised by Braggins and Talbot (2003:17) who found that sentencing plans were considered by prisoners to be target-setting exercises and that programme choice was limited by 'what the prison would or would not allow'. Therefore, the recommendation of 
Coates (2016:14) that prisoners need to '...feel both that they have real ownership of their Personal Learning Plan and that they have responsibility for engaging in the necessary activity to achieve it', is a salient one supported by the findings of this study. Equally important is the fact that while sentencing plans are a fundamental tool for mapping out an individual's rehabilitative needs, and are constructed by experienced Offender Managers who are trained to identify such needs, the extent to which this is a negotiated process between prisoner and Offender Manager is a moot point. The second relates to non-NOMS accredited programmes for rehabilitation. The fact that the Chrysalis Lite programme was not NOMS accredited meant that it could not be formally added to the participants' sentencing plan and while some participants' Offender Managers did so because they believed it would be useful for their client's progression, most participants opted to do the programme rather than being told to. This suggests that participants in this study viewed rehabilitation as more than simply 'doing as instructed' by their Offender Manager or sentencing plan, in turn demonstrating that personal responsibility and ownership of their rehabilitation was important to them.

The accreditation of programmes by NOMS leads to the second potential difficulty with adopting more innovative and less restrictive programmes; utilising entry criteria or requirements orientated around prior educational achievement. Traditional rehabilitative programmes, such as TSP have specific prerequisites that often exclude those most in need of thinking skills support from attending the programme. In contrast, the Chrysalis Lite programme follows similar criteria to the POP programme (Clark and Duwe, 2015) outlined earlier, therefore making the programme more inclusionary and capturing a wider range of the target population. Given Coates' (2016) observation of the low educational accomplishment of prisoners arriving in prison and that many fail to leave prison with significant improvement, the use of less prescriptive and more fundamental life skills programmes like Chrysalis Lite may be of benefit. For example, the findings suggest that regardless of the participant's literacy, maths and IQ level, they were able to learn what they believed were valuable life skills that would help them in the future, including effective communication, improved confidence, and working with others. In addition, the emphasis on 'living in the gap' highlighted by nearly all the participants suggest that developing basic life skills such as self-awareness and self-esteem, life planning and problem-solving, interpersonal skills including communication and presentation, and pausing to think can improve behaviour and attitudes regardless of prior educational attainment. Lastly, attaining wider educational and vocational targets might be made easier if basic life skills are incorporated into rehabilitation, as shown by those participants who noted the use of these skills to engage with education, work, or wider initiatives including mentoring. This last point is reflective of the arguments posed by other researchers (see Behan, 2014; Keena and Simmon, 2015; McNeil, 2006; Warr, 2016; 
and Weaver, 2015) that key life lessons better prepare prisoners for re-entering society and thus may have an impact on reoffending and rehabilitation.

Regardless of the challenges of offering basic life skills provisions in prison, the se findings suggest that prisoner's consider basic life skill development a necessary part of rehabilitation that could positively impact educational achievement while also improving more immediate behavioural and thinking skills issues. One of the key findings of this study was the participants reporting that their attitudes and subsequent behaviour had been significantly improved because of what they referred to as living in the gap. Prison staff also observed these changes noting visible changes in some prisoner's behaviour within the first few weeks. This suggests that participants were not just repeating what they had been taught to say, as argued by Gobbett and Sellen (2013) and Behan (2014) in relation to thinking skills programmes, but were internalising their learning and thus changing thinking and behaviour simultaneously. Furthermore, the references to reduced violent feelings by some of the participants presents some optimism that Chrysalis is facilitating a positive change in behaviour amongst programme participants. Such findings therefore present an opportunity to further examine the impact that life skills programmes may have on violence within prisons, and thus go some way towards addressing escalating concerns about how to tackle the prevalence of violence across the prison system.

The present study offers insight into the basic life skills programme being offered to adult prisoners within one prison in England. The findings contribute to the body of knowledge around rehabilitative programmes available for prisoners and goes some way towards addressing the absence of alternative programmes offered in the UK prison system. In the absence of wider UK based research surround ing basic life skills programmes, it is difficult to say whether the benefits reported by participants will be sufficient to achieve long term, sustainable change outside of prison. However, as the data gathered was from current cohort participants and programme completers at this institution, it is likely that the programme has some impact on behaviour, thinking, planning, and presentation while in prison. For example, some of the life skills taught such as planning, thinking before reacting, and understanding oneself were viewed by the participants as new skills but useful for life. Although more research in this area is needed, many prisoners appear to lack basic life skills therefore a greater understanding of the place of basic life skills in relation to wider educational achievement and reoffending is needed. Therefore, to make any headway with reducing reoffending rates rehabilitation programmes need to be re-examined, firstly to take account of what is being delivered and the participants view on its usefulness. Secondly to consider whether participants have the necessary basic life skills to engage 
with a programme in a meaningful way, and thirdly the extent to which institutional delivery and restrictions hamper prisoners' ability to develop the necessary autonomy to transform their lives.

\section{References}

Apparicio, D. (2015), “Chrysalis Programme Evaluation: Chrysalis Lite from September 2009 to May 2015", Unpublished Self Evaluation, Chrysalis Foundation Records, Northampton.

Barrett, G. (2008), Gender responsivity and the new thinking skills programme: A qualitative evaluation of the thinking skills pilot with female offenders, Ministry of Justice, London.

Behan, C. (2014), "Learning to Escape: Prison Education, Rehabilitation and the Potential for Transformation", Journal of Prison education and Reentry, Vol.1, No.1, pp. 20-31.

Benson, M. (2013) Crime and the Life Course. Routledge, London.

Blud, L. and Treavers, R. (2001), "Interpersonal problem-solving skills training: A comparison of R\&R and ETS”, Criminal Behaviour and Mental Health, Vol. 11 No.4, pp. 251-361.

Boyatzis, R. (1998), Transforming Qualitative Information: Thematic Analysis and Code Development. Sage, London.

Braggins, J. and Talbot, J. (2003), Time to Learn: Prisoners' Views on Prison Education. Prison Reform Trust, London.

Bryman, A. (2008), Social Research Methods. Oxford University Press, Oxford.

Cann, J., Falshaw, L., Nugent, F., and Friendship, C. (2003), Understanding What Works: Accredited Cognitive Behavioural Skills Programmes for Adult Men and Young Offenders (Home Office Research Findings No.226), Home Office, London.

Clark, V. and Duwe, G. (2015), "An Outcome Evaluation of a Prison-Based Life-Skills Program: The Power of People", International Journal of Offender Therapy and Comparative Criminology, Vol.59 No.4, pp.384-405.

Coates, S. (2016), Unlocking Potential: A review of education in prison. Ministry of Justice, London.

Collinwood, D. (2010), The 7 Habits on the Inside: Reducing Recidivism Through Behavioural Change, Salt Lake, Franklin Covey.

Cullen, F. (2013), "Rehabilitation: Beyond Nothing Works". Crime and Justice. Vol. 42 No. 1, pp. 299375. 
Falshaw, L., Friendship, C., Travers, R., and Nugent, F. (2003), Searching for 'What Works': an evaluation of cognitive skills programmes (Home Office Research Findings No. 206), Home Office, London.

Friendship, C., Blud, L., Erikson, M. and Travers, R. (2002), An evaluation of cognitive behavioural treatment for prisoners (Home Office research findings No.161), Home Office, London.

Gobbett, M. and Sellen, J. (2014), "An Evaluation of the HM Prison Service "Thinking Skills Programme" Using Psychometric Assessments", International Journal of Offender Therapy and Comparative Criminology, Vol. 58 No. 4, pp. 454-473.

Harris, D and Riddy, R (2008), The thinking skills programme: Theory manual (Interventions and Substance Misuse Group), Ministry of Justice, London.

Hurry, J., Rogers, L., Simonot, M. and Wilson, A. (2012), Inside Education: The Aspirations and Realities of prison education for under 25s in the London area. A Report for Sir John Cass's Foundation, Institute of Education, University of London, London.

Keena, L. and Simmons, C. (2015), "Rethink, Reform, Re-enter: An Entrepreneurial Approach to Prison Programming", International Journal of Offender Therapy and Comparative Criminology, Vol. 59 No. 8, pp. 837-854.

Laub, J. and Sampson, R. (2001), "Understanding desistance from crime", Crime and Justice, Vol.28, pp.1-69.

MacKenzie, D.L., Bierie, D. and Mitchell, O. (2007), "An experimental study of a therapeutic boot camp: Impact on impulses, attitudes and recidivism". Journal of Experimental Criminology, Vol.3 No. 3, pp. 221-246.

McNeil, F. (2006), "A Desistance Paradigm for Offender Management", Criminology and Criminal Justice, Vol. 6 No. 1, pp. 39-62.

Ministry of Justice. (2013), Transforming Rehabilitation: A Strategy for Reform, The Stationary Office, London.

Ministry of Justice. (2015a), Accredited Programmes Annual Bulletin 2014/15, England and Wales, Ministry of Justice, London.

Ministry of Justice. (2015b), Proven Re-offending Statistics Quarterly Bulletin: January to December 2013, England and Wales, Ministry of Justice, London.

Ministry of Justice. (2017), "Population Bulletin: Weekly 17 February 2017". Available at: www.gov.uk/government/statistics/prison-population-figures-2017 (accessed 17 February 2017). 
Riddy, R. (2010), The Thinking Skills Programme (NOMS Interventions and Substance Misuse group), Ministry of Justice, London.

Rogers, L., Simonot, M. and Nartey, A. (2014), "Prison Educators: Professionalism against the Odds", available at: http://www.ucu.org.uk (accessed 4 November 2015).

Semmens, N. (2011), "Methodological Approaches to Criminological Research", in Davies, P., Francis, P. and Jupp, V., (Eds.), Doing Criminological Research, Sage, London.

Social Exclusion Unit. (2002), Reducing re-offending by ex-prisoners, Social Exclusion Unit, London.

Travers, R., Mann, R., and Hollins, C. (2014), "Who benefits from cognitive skills programs? Differential Impact by Risk and Offence Type", Criminal Justice and Behaviour, Vol. 41 No. 9, pp. 1103-1129.

Warr, J. (2016), "Transformative Dialogues: (Re)privileging the informal in prison education", Prison Service Journal, Vol. 225, No.18, pp. 18-25.

Weaver, B. (2015), "Being Imprisoned: Punishment, Adaptation and Desistance", European Journal of Probation, Vol. 7 No. 3, pp. 263-264.

Williams, K., Papadopoulou, V. and Booth, N. (2012), "Prisoners' childhood and family backgrounds" available at: https://www.gov.uk/government/uploads/system/uploads/attachment_data/file/278837/prisonerschildhood-family-backgrounds.pdf (accessed 02 February 2017).

Wolfgang, M.E., Thornberry, T.P. and Figlio, R.M. (1987), From Boy to Man, from Delinquency to Crime, The University of Chicago Press, London.

World Health Organisation. (1999), Partners in Life Skills Education, Department of Mental Health, Geneva. 